\title{
Conexões entreo federalismo fiscal e o financiamento da política de saúde no Brasil
}

\author{
Connections between fiscal federalism \\ and the funding of the Brazilian health care policy
}

1 Departamento de Administração e Planejamento em Saúde, Escola Nacional de Saúde Pública Sérgio Arouca, Fundação Oswaldo Cruz. Rua Leopoldo Bulhões 1480, Manguinhos. 21041-210 Rio de Janeiro RJ.

luciana@ensp.fiocruz.br
Abstract In theBrazilian society's context of meager financial resources for health care, associated with structural features of fiscal federalism and with the current model of funding transfers for the Unified Health System's (SU S), important inequities directly impact political negotiations and the deployment of federal financingalternatives which are not directly linked to the supply and production of health care activities and services by states and municipalities. We observed that health policies, since the second half of the nineties, have developed their own mechanisms that, in the above mentioned context, tend to accommodate different interests and federative conflicts generated by structural factors and by institutional rules. However, the absence of an integrated planning program between the criteria to establish resource re distribution for financing the Unified Health System and the Brazilian Federation's fiscal sharing system, end up reinforcing certain asymmetric patterns and generating new imbalances, making the compensation of inequities difficult in public health spending at the sub-national domain.

Key words Fiscal federalism, $\mathrm{H}$ ealth financing, Health policy
Resumo As expressivas desigualdades da socie dade brasileira e o contexto de escassez de recursos financeiros para o setor da saúde, associados às características estruturais do federal ismo fiscal e ao modelo predominante das transferências do SUS, influenciam a negociação política eimplantação dealternativas definanciamento federal não atreladas diretamenteà oferta eprodução deações e serviços de saúde nos estados e municípios. Observa-se que a política de saúde, a partir da segunda metade da década de 1990, vem desenvolvendo mecanismos próprios que, neste contexto específico, tendem a acomodar interesses diver sos e conflitos federativos gerados por fatores estruturais e pelas regras institucionais. Porém, a falta de um planejamento integrado entre os critérios que regem a redistribuição dos recur sos para o financiamento do Sistema Ú nico de Saúde e o sistema de partilha tributário da federação brasileira acaba por reforçar determinados padrões de assimetria encontrados e gerar novos desequilíbrios, dificultando a compensação das desigualdades na capacidade de gasto público em saúde das esferas subnacionais.

Palavras-chave Federalismo fiscal, Financiamento da saúde, Política de saúde 
Introdução

0 tema federalismo, relações intergovernamentais e políticas públicas vêm se tornando objeto de interesse crescente da produção científica brasileira e internacional. Em que pese a ampliação das publicações sobre o tema, em grande parte, os trabalhos apóiam-se em diferentes enfoques, que tratam de maneira diversa o papel das instituições na vida política etendem a separar as variáveis econômico-financeiras das variáveis políticas. Não há, ainda, uma produção nacional consistente que busque relacionar determinados arranjos institucionais do Estado com políticas específicas. Reconhecendo as lacunas existentes, este artigo visa contribuir para a discussão das conexões entre o federalismo e a política de saúde no Brasil, a partir do referencial teórico-metodológico proposto por Gagnon ${ }^{1}$ e Souza C. ${ }^{2}$.

Gagnon ${ }^{1}$ considera que o sucesso dos sistemas federativos deve ser medido por sua capacidade de regular conflitos, já que suas instituições, por serem sensíveis à diversidade, atuam no sentido de amenizar as tensões da sociedade. Para este autor, é necessário refletir sobre as relações entre as regras institucionais e os conflitos intergovernamentais, a forma pela qual as esferas de governo se articulam e negociam suas divergências e quais os resultados deste processo denegociação.

Na mesma linha, SouzaC. ${ }^{2}$ adverte que as investigações sobre o comportamento dos atores federativos não podem prescindir da tarefa de desvendar as "regras do jogo", que intervém no comportamento político dos atores. Ou seja, descobrir os constrangimentos impostos aos atores em suas escolhas. Os aspectos institucionais são importantes porque determinam a capacidade de atuação dos agentes políticos, condicionam sua percepção acerca das alternativas realistas da política e incidem em suas opções estratégicas e preferências.

Sob este enfoque, propõe-se identificar alguns limites e constrangimentos institucionais impostos ao financiamento público da saúde no Brasil. Uma primeira ordem de fatores diz respeito à forma como se estrutura a divisão das competências tributárias (que nível de governo administra e arrecada cada tributo) e os dispositivos que determinam a partilha intergovernamental de recursos no federalismo fiscal brasileiro. A segunda refere-se ao modus operandi das transferências federais para o financiamento das ações e serviços descentralizados do Sistema Único de Saúde (SUS), que respeitam, na sua maioria, a capacidade instalada e a produção de ações e serviços de saúde nos estados e, principalmente, nos municípios.

Estes dois fatores, em um Estado marcado por acentuadas desi gual dades socioeconômicas e um contexto de escassez de recursos para a saúde, têm moldado o posicionamento dos atores federativos e relações de cooperação e conflito, estimulando a criação de novos critérios e mecanismos de redistribuição de recursos federais a partir da segunda metade da década de 1990. D essa forma, acredita-se que a política de saúde vem desenvolvendo mecanismos próprios queinteragem, num contexto específico, com variáveis estruturais e institucionais de difícil modificação pelos atores que atuam no setor da saúde.

Neste trabalho, através do levantamento da produção bibliográfica recente e da análise de dados secundários, discute-se sobre os temas federalismo fiscal efinanciamento federal da política de saúdeno Brasil, identificando-se suas principais características, as alterações operadas ao longo dos anos 90 einício dos anos 2000, as relações existentes e seus desdobramentos.

Federalismo fiscal à brasileira: características das mudanças implantadas a partir dos anos 80

Para entendemos a realidade brasileira, é preciso refletir sobre as bases do modelo de federalismo fiscal implantado. É consenso entreos estudiosos sobreo tema queo modelo atual repousa nos fundamentos da reforma de 1967 e que os conflitos hoje vividos no terreno tributário se dão pelas modificações incompletas do mesmo, em uma conjuntura política e econômica completamente diversa.

A reforma de 1967 caracterizava-se por: 1) forte centralização da arrecadação tributária no governo federal, principal responsável pelo estímulo ao desenvolvimento da economia; 2) reforço da capacidade tributária própria de estados e municípios, com a criação do Imposto sobre Circulação de Mercadorias (ICM) na competência dos estados e do Imposto sobre Serviços (ISS) na competência dos municípios; 3) implantação de mecanismo de repartição regular de receitas federais com fins redistributivos e não-condicionados a gastos específicos - os Fundos de Participação dosEstados (FPE) e Municípios (FPM ); 4) implantação demecanismo de alocação de receitas federais para investimentos, caracterizado por forte vinculação setorial efuncional (despesas de 
capital) - as devoluções tributárias dos impostos sobre combustíveis, energia elétrica, minerais e comunicação que se destinavam às empresas públicas federais, estaduais e municipais; 5) criação de mecanismo de devolução tributária do ICM para os municípios ${ }^{3,4}$.

Seconcebido com uma orientação descentralizadora, o sistema tributário brasileiro foi gradualmente modificado ao longo dos anos da ditadura, de modo a concentrar o controle sobre a receita e a alocação do gasto no âmbito federal. Novas condicionalidades e vinculações vão sendo atreladas aos Fundos de Participação, reduzindo a liberdade orçamentária das unidades subnacionais e direcionando os recursos para programas ou funções específicas.

A centralização associada à perda de autonomia dos governos subnacionais do período de 1968 até 0 final dos anos 70 desencadeou uma forte reação contrária no processo de abertura política dos anos 80, onde os municípios e estados ganham gradativamente espaço para atendimento de suas demandas e revisão do sistema tributário brasileiro. Dain ${ }^{5}$ enfatiza que, nesta época, a dimensão federativa se impôs aos demais aspectos relativos à reformulação do sistema tributário brasileiro.

Em relação às competências tributárias, amplia-se o papel das esferas subnacionais na arrecadação tributária e sua autonomia na gestão dos impostos. Esta ampliação se deu por diversos mecanismos na década de 1980 . Um, relacionado ao aumento de abrangência do ICM com a criação do Imposto sobre Circulação de M ercadorias e Serviços (ICMS). Este passou a incluir os impostos únicos federais (combustíveis, energia elétrica, minerais, comunicação e transporte). Além disso, o controle central observado sobreo imposto é retirado e os governos estaduais passam a ter maior responsabilidade pela sua gestão.

0 dispositivo que definia a partilha neutra do antigo ICM também éalterado: $25 \%$ da cota-parte do ICM e, posteriormente, do ICM S são objeto de livre disposição por lei estadual. Os $75 \%$ restantes da cota- parte permanecem regidos pelo mecanismo de devolução tributária. Isso representou um aumento do poder do estado na alocação municipal deste tributo que passa a incorporar um componente redistributivo à fórmula do repasse.

Por outro lado, a Constituição de 88 estabelece como atribuição dos estados a composição e definição dos valores das alíquotas do ICM S. Os governos estaduais passam a utilizá-lo como instrumento de política econômica para atração de novos investimentos em prejuízo do objetivo arrecadatório, fenômeno esse denominado de "guerra fiscal" dos estados nos anos 90.

No plano municipal, o reforço das receitas diretamente arrecadadas também se verifica. M esmo tendo sido frustradas as tentativas de incorporação do ISS ao ICMS, são mantidas na Constituição os mecanismos de compensação para os municípios 5 . Entre eles, a criação do Imposto sobre Vendas a Varejo de Combustíveis (IVVC), que foi extinto posteriormente, 0 aumento de $20 \%$ para $25 \%$ do percentual de partiIha do ICM S para as esferas locais e o compartiIhamento com o estado da arrecadação do antigo imposto sobre a transmissão de ben simóveis. 0 governo estadual passa a arrecadar o imposto de heranças e doações e os governos municipais o imposto de transmissão "inter vivos" de bens imóveis.

Dain ${ }^{55}$ também aponta para outros mecanismos de compensação implementados em função de reformas não levadas à cabo pelos constituintes em 1988. Havia na época uma proposta de adoção de um princípio único de destino na aplicação do ICMS, com desoneração das exportações internas e externas. Com esta proposta, perderiam os estados exportadores líquidos. M esmo mantendo-se a tributação do imposto na origem edestino, foi inevitável estabelecer compensações visando reduzir os impactos perversos do sistema tributário sobre a competitividade do setor produtivo brasileiro ea falta deinvestimento. Daí resultam o Fundo de Compensação pela Exportação de Produtos Industrializados (FPEX) - que redistribui $10 \%$ da arrecadação do Imposto sobreProdutos Industrializados (IPI) da União em função do volume de exportações das UFs - e, posteriormente, a Lei Complementar (LC) 87/96 (Lei Kandir) quecomplementa a desoneração das exportações para ou tros produtos. Estas medidas acabaram por incidir também nas receitas dos municípios, pois a legislação prevê que $25 \%$ dos recursos das transferências compensatórias dos estados sejam repassados aos seus municípios ${ }^{4}$.

Um segundo componente importante das mudanças operadas a partir dos anos 80 diz respeito ao sistema de partilha tributária. Como afirma Rezende³, a "bandeira da descentralização" estampava a reivindicação do aumento das transferências federais sem qualquer condicionalidade quanto ao seu uso. No modelo de partilha da reforma de 1967, estas transferências se constituíam através do FPE e do FPM que possuíam capacidadelivre de gasto pelas instâncias subnacionais. A segunda perna do sistema - os mecanis- 
mos de devolução dos impostos únicos arrecadados pela União -, que cuidava da cooperação intergovernamental no tocanteà implementação das políticas prioritárias para o desenvolvimento, não atendia ao preceito de maior autonomia, pois direcionava os recursos para determinados setores da economia e restringia-se a despesas de capital.

Em decorrência, cresce a parcela da receita federal do Imposto de Renda (IR) e do IPI que compõem os Fundos de Participação. 0 crescimento éde tal monta que passa a absorver, a partir de 1993, quase a metade da arrecadação dos principais tributos de competência da União: $21,5 \%$ da receita líquida do IR e do IPI constituem o FPE e $22,5 \%$ o FPM ${ }^{6}$. A "amputação da perna" da cooperação, atrelada à hipertrofia das transferências redistributivas e à atrofia de outros incentivos fiscais ao desenvolvimento regional, comprometeram o equilíbrio do modelo de partilhas previsto em $1967^{3}$.

Por outro lado, os critérios utilizados como base para redistribuição dos recursos do FPE e FPM permanecem basicamente os mesmos de 1967. Em relação ao FPE, vigoram o tamanho da população eo inverso da renda per capita. Para o FPM , o mecanismo de repartição dá direito a 10\% dos recursos às capitais e, para os demais municípios, leva em consideração o porte populacional, privilegiando os menores com dotações que se reduzem à medida que cresce o tamanho da população.

Em 1981, os critérios de distribuição do FPM são parcialmente remodelados. Do valor líquido do FPM , 10\% são distribuídos entre as capitais, $86,4 \%$ entre os demais municípios do interior e 0 restante de forma adicional para os municípios do interior com mais de 156.216 habitantes. Segundo Prado ${ }^{4}$, esta mudança representa uma tímida tentativa de lidar com o viés criado pelas regras originais que favoreciam os pequenos municípios e colocavam em desvantagem localidades com problemas metropolitanos.

Outras modificações são estabelecidas pela Lei Complementar (LC) 62/89 que define que $85 \%$ dos recursos do FPE devem ir para os estados das regiões Norte $(25,37 \%)$, Nordeste $(52,46 \%)$ e Centro-Oeste $(7,17 \%)$ e $15 \%$ para os demais estados das regiões Sul $(6,52 \%)$ e Sudeste $(8,48 \%)$. No que se refere ao FPM, este passa a ser distribuído para os municípios do interior por um coeficiente fixo diferenciado por estado. Para as capitais, um coeficiente individual orienta a distribuição dos 10\% do FPM independente de sua localização.
0 efeito esperado com a medida, de restrição à multiplicação municipal devido às regras de rateio do FPM , se contrapõe à importante atuação destes fundos enquanto mecanismo para redistribuição de recursos que reflita a evolução no tempo das necessidades sociais e demandas por políticas e serviços públicos. Como os critérios passam a ser estáticos, o mecanismo de correção dos desequilíbrios horizontais a favor de patamares mais homogêneos de receitas e capacidades degasto entre estados e regiões fica comprometido. Apenas no que se refere à distribuição de re cursos nos municípios do interior do estado o sistema mantém al guma dinamicidade.

\section{Efeitos do modelo de federalismo fiscal sobre o financiamento do Sistema Ú nico de Saúde na década de 1990}

M uitas são as críticas formuladas pelos especialistas do federalismo fiscal sobre o sistema tributário vigenteno Brasil. Enfatizaremos aqui as que julgamos fundamentais para compreensão das repercussões sobre o financiamento da política de saúde até 0 início dos anos 2000.

A primeira delas diz respeito aos conflitos gerados entre o poder central e as instâncias subnacionais de governo pela forma como se conduziu o processo de descentralização do sistema tributário. Podemos afirmar que o sistema tributário brasileiro, pelas regras atuais, está entre um dos mais descentralizados do mundo, tanto no quese refereao poder de tributação como degasto auferidos às instâncias subnacionais. Segundo dados produzidos em estudo sobre a partilha de recursos tributários no Brasil, o governo federal arrecadava em 2000 cerca de $67 \%$ do total das receitas tributárias (Gráfico 1), transferindo cerca de $35 \%$ de suas receitas para estados e, principalmente para os municípios, na forma de transferências redistributivas livres ou setorialmente orientadas?.

Embora a função de redistribuição de recursos seja um importante mecanismo para correção dos desequilíbrios fiscais pelo poder central em países heterogêneos como o Brasil, ressaltase que o processo de descentralização operado a partir dos anos 80 não contou com uma descentralização planejada de encargos. Por sua vez, 0 modelo de Seguridade Social preconizado para o Brasil exige a coordenação do nível federal na implementação de políticas que promovam o desenvolvimento econômico e compensem as carências e dificuldades institucionais próprias das esferas subnacionais. 
Gráfico 1

Distribuição da receita total arrecadada e da receita final entre as diferentes esferas de governo,

Brasil - 2000.

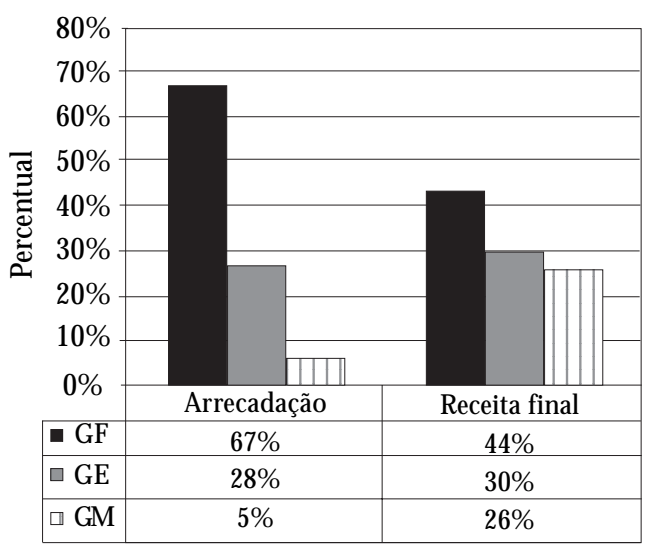

Fonte: Elaboração própria a partir de dados obtidos de Prado 4 .

Nota: GF - governo federal; GE - governos estaduais; GM governos municipais.

A perda de recursos da União provocou uma reação duplamente prejudicial para a política social. Por um lado, fez com que o governo federal se desinteressasse pelas modificações do IR, já que grande parte dos recursosprovenientes do imposto são transferidos a estadosemunicípios. Isto faz com que uma fonte importante de receita para a implantação de políticas no âmbito local permaneça com sérios problemas em relação à estreiteza de sua base de arrecadação, aos benefícios que diminuem o seu valor nominal e sua progressividade. Por outro ângulo, a esfera nacional acabou por investir na ampliação das contribuições sociais para o financiamento da Seguridade Social.

Dain et al. ${ }^{8}$ demonstram que, na atual estrutura tributária brasileira, 0 alto peso das contribuições sociais em relação aos impostos sobre o valor adicionado e aos impostos diretos sobre renda e propriedade causam um desequilíbrio na composição da carga tributária. Em 1998, as contribuições sociais para o financiamento da SeguridadeSocial representavam cerca de $10 \%$ do PIB, sendo responsáveis pelo maior montante de recursos arrecadados e atuando como principal fonte de receita disponível para cobrir os gastos da União.

Ante ao decréscimo da receita de impostos e à não apropriação dos recursos das contribuições sobre os salários vinculados à Previdência Social em 1993, o governo acabou lançando mão de outros dispositivos para ampliar sua receita disponível. Entre eles, o aumento das alíquotas e a imposição de impostos cumulativos e superpostos, como a Contribuição para o Financiamento da Seguridade Social (COFINS), a Contribuição sobre o Lucro Líquido das Empresas (CSLL) e o Programa de Integração Social/Programa deFormação do Patrimônio do Servidor Público (PIS/ PASEP), além da implantação de novos tributos, como é o caso da Contribuição Provisória sobre a Movimentação Financeira (CPMF) em 1997. Apesar de não sofrerem perda inflacionária significativa, as contribuições sociais geram danos à competitividade sistêmica, onerando desigualmente produtos, setores e empresas e causando grandes questionamentos jurídicos e evasão da arrecadação esperada.

A importância das contribuições sociaistambém cresceu na medida em que estes recursos foram contigenciados pela União visando a manutenção do plano de estabilização econômica pelo governo e o pagamento da folha de inativos. Lessa et al. ${ }^{9}$ ressaltam que, entre 1993 e 1995, foram contingenciados $20 \%$ dos recursos da Seguridade Social para o Fundo Social de Emergência. O utro aspecto destacado pelos autores refere-se à su peração dos recursos destinados ao pagamento dosEncargos Previdenciários da União (EPU) frente aos recursos destinados ao M inistério da Saúde (MS). Entre 1994 e 1995, a rubrica EPU recebeu, respectivamente, $16,5 \%$ e $23,3 \%$ do total dasfontes da Seguridade, enquanto quea saúde, nos mesmos anos, levou 18,6\% e 19,6\% das fontes. Segundo os dispositivos constitucionais, as despesas relativas às aposentadorias dos servidores federais não dizem respeito à previdência social da Seguridade Social, pois o regime desses trabalhadores foi mantido à parte.

A base de financiamento da Seguridade Social ficou comprometida, assim como o processo de descentralização das políticas sociais previsto na Constituição de 1988, pois, mesmo aportando recursos próprios para o setor, os governos subnacionais dependem dosrecursos oriundos do orçamento do M S para suprir suas necessidades de gasto. Silva ${ }^{10}$ destaca que a proposta de descentralização foi revertida na década de 90 devido à: 1) diminuição da participação das instâncias subnacionais na receita tributária da União (21\% para $15 \%$ de 1988 a 1996), porque os tributos partilhados (IR e IPI) não acompanharam a evolução da receita da União; 2) perda da autonomia dos estados pela subordinação do FPE ao pagamento das dívidas retroativas com a União, 
submetidas às elevadas taxas de juros da política econômica do governo; 3) contingenciamento dos recursos da Seguridade Social erecentralização dos recursos disponíveis para as instâncias subnacionais, através dos atrasos na liberação e criação dos Fundos Social de Emergência e de Estabilização Fiscal eda D esvinculação de Recursos da União (DRU).

Em que pese as considerações acima, os municípios foram ben eficiados pelas mudanças operadas. Sua capacidade de gasto foi ampliada nas duas últimas décadas, enquanto os estados permanecem hoje com a mesma disponibilidade líquida de recursos que tinham há 20 anos.

Prado ${ }^{4}$ relata que os estados desempenham uma importante função na arrecadação tributária nacional. A importância da arrecadação na receita final dos estados também é significativa (cerca de $90 \%$ de sua receita final). No entanto, os estados, assim como a União, arrecadam mais do que ao fim do processo Ihes resta como receita fiscal, já que transferem aos municípios uma grande parte da receita do ICM S. Das transferências totais cedidas pela União, a maior parte vai para os municípios na forma do FPM. Neste cenário, não é de se surpreender que os estados tenham lançado mão de seu poder de gestão sobre as principais variáveis do ICM S para atrair novos investimentos na tentativa malfadada de aumentar suas receitas.

A pesar da importância do ICM S, a dependência dos municípios em relação ao governo federal émaior. Desua receita final, $80 \%$ dos recursos são derivados de transferências e, dessas, $50 \%$ se originam da União $0^{4}$ Isso leva a uma grande fragilidade das conexões administrativas e orçamentárias existentes entre os municípios eos estados. 0 padrão que predomina privilegia as articulações entre o governo central e cada um dos governos municipais, o que dificulta a integração de políticas e a formação de redes de serviços.

Por último, cabe refletir sobre os resultados atrelados às transferências redistributivas. Estes fluxos não guardam relação com a base econômica local e permitem reduzir desigualdades na capacidade de gasto através da real ocação de recursos entre as esferas subnacionais. Segundo Prado ${ }^{4}$, cerca de $68 \%$ do volumetotal de transferências intergovernamentais verificados no sistema brasileiro se encaixam nesta categoria. Entre eles, temos aqueles considerados fluxos redistributivos clássicos, que podem ser utilizados na forma livre de gasto pelas esferas subnacionais: os Fundos de Partici pação, que representam cerca de $41 \%$ do total de recursos redistributivos do sistema; o sistema cota- parte estadual que inclui os $25 \%$ do ICM S distribuídos segundo critérios definidos em lei estadual e os $25 \%$ do FPEX e da LC 87/96. Este subsistema correspondeà $9,4 \%$ do total das transferências redistributivas.

Podemos ainda agregar as transferências redistributivas setoriais da União, ou seja, aquelas quese restringem a funções específicas e não atuam diretamente sobre a capacidade geral de gasto do orçamento receptor, pois interferem apenas na alocação de recursos públicos destinados a dois dos principais setores de atuação do setor público: a educação (as transferências do Fundo Nacional de Desenvolvimento do Ensino Fundamental eValorização do M agistério - Fundef) ea saúde (as transferências SUS). Enquanto o Fundef representa cerca de $30 \%$ dos recursos redistributivos totais transferidos, o SUS representa cerca de $20 \%$.

0 sistema de partilha redistributivo no Brasil reforça a função da União em detrimento dos estados na realocação dos recursos que tenham potencial para equalização fiscal. Mas a pergunta fundamental a ser feita é se ele, tal como está estruturado, possibilita a equalização horizontal da capacidade orçamentária de gasto entre as esferas subnacionais.

A primeira conclusão que tiramos do estudo conduzido por Prado 4 é que existem determinadas regras que limitam a transferência de recursos redistributivos aos estados. É o que o autor denomina de "redistribuições internas". Neste subtipo, enquadram-se o sistema cota-parte estadual euma parte dos recursos do Fundef (Fundef estadual interno). Estes recursos têm possibilidades de cumprir funções realocativas apenas entre os municípios que compõem um dado estado, não podendo atuar na redução das desigualdades interestaduais ou inter regionais.

As evidências indicam que o FPE tende a ser mais redistributivo que o FPM no plano interregional, proporcionando ganhos substantivos de receita nas regiões N orte, N ordesteeCentro-O em detrimento das regiões Sudeste e Sul do país. Entretanto, a redistribuição do FPE não é suficientepara homogeneizar a capacidade de gasto relativa entre estados situados na mesma região do país. O bservam-se importantes disparidades na receita final per capita (resultado da arrecadação e do sistema de partilha como um todo) que não se justifica facilmente por variações na renda ou no nível de desenvolvimento entre os estados.

No plano dos municípios, a referida pesquisa também demonstra que as disparidades encontradas na receita final per capita entre as capitais 
emunicípios de porte populacional diferenciado são gritantes. Detal monta que: 1) o sistema privilegia claramente as capitais ( $23 \%$ da população) eosmunicípiosabaixo de 5.000 habitantes $(2,7 \%$ da população) em relação aos municípios na faixa de 10.000 a 100.000 habitantes (41\% da população); 2) a receita per capita das capitais é $80 \%$ mais al ta quea enorme parcela da população que reside em municípios intermediários; 3) os municípios com população abaixo de 5.000 habitantes têm uma receita per capita superior às capitais; 4) o crescimento da receita nos municípios com mais de 75.000 habitantes não está associado à arrecadação ou ao FPM mas, fundamentalmente, pela devolução tributária e pelos demais fluxos redistributivos fora o FPM.

De fato, a falta de um planejamento integrado do sistema de partilha dos recursos redistributivos no Brasil, assim como as mudanças que aconteceram pela fixação dos coeficientes dos Fundos de Participação e a variedade das regras que orientam cada um destes fluxos dificultam a correção de assimetrias.

Este último aspecto traz à tona a importância dos fluxos redistributivos setoriais e, particularmente, as transferências SU S. Estas transferências são orientadas para a provisão de ações eserviços específicos e possuem uma lógica interna própria que não parece se integrar com o restante do sistema de partilha, pois as transferências SUS não são planejadas como um componente do sistema de partilha tributária brasileiro. Pelo contrário, o maior ou menor poder de redução das desigual dades das transferências SU S depende da forma como vem se institucionalizando o subsistema na política de saúde. A pesquisa de Prado ${ }^{4}$ mostra que o efeito redistributivo dos recursos transferidos via SUS são também restritos. Eles beneficiam as regiões Sudestee Sul enão se diferenciam significativamente nos municípios de porte intermediário e as capitais, apresentando um potencial limitado para redução das desigual dades na capacidade de gasto das esferas subnacionais.

\section{O modelo de transferência federal do SUS}

A legislação que instituiu o SUS definiu as bases do modelo de transferência de recursos federais para os governos subnacionais, tendo em vista o financiamento das ações e serviços descentralizados de saúde. Ela estabelece que os recursos sejam transferidos de forma regular e automática, do Fundo Nacional deSaúdeaos Fundos Estadu- ais de Saúde (FES) e Municipais (FMS), observando-se critérios diversos - perfil demográfico eepidemiológico da população, características da rede de serviçcos de saúde, desempenho no período anterior, níveis de participação da saúde nos orçamentos municipais e estaduais, previsão de investimentos, ressarcimento do atendimento prestado a outras esferas de governo - , com ênfase na definição de montantes per capita (não menos que a metade dos recursos transferidos). Além disso, preconiza que os recursos transferidos sejam destinados a investimentos na rede de serviços, cobertura assistencial e hospitalar e demais ações e serviços de saúde.

As transferências do SUS têm início somente em 1994, após quatro anos da publicação das Leis. Na prática, a publicação de centenas de portarias federais, entreelas as Normas 0 peracionais ( $\mathrm{NO}$ ) do SUS, acabaram por alterar o padrão de transferência federal originalmente proposto. Ugá et al. ${ }^{11}$ enfatizam que as mudanças operadas privilegiaram mecanismos e critérios distintos de transferências, segundo o tipo de serviço ou programa, ao invés da idéia original de repasses globais não fragmentados.

Até meados de 2004, observa-se a consolidação de um modelo diversificado de transferências "fundo a fundo". Nele coexistem mecanismos que não estão associados diretamente à prestação de serviços e são realizados independente do quantitativo deações eserviços produzidos ( $\mathrm{me}$ canismos de transferência pré produção) e me canismos que atrelam as transferências à informação prévia da produção (mecanismos detransferência pós-produção).

Quanto aos critérios que definem os recursos federais transferidos mensalmente para municípios e estados, estes se diferenciam em:

1. critérios per capita utilizad os para o financiamento de um conjunto ações de atenção básica. Nesta modal idade incluem-seo Piso da Atenção Básica fixo (PAB fixo), implantado em 1998 e variando entre $R \$ 10,00$ a $R \$ 18,00$ reais per capita/ano e, a partir de 2002, o Piso da Atenção Básica Ampliado (PAB-A), definido em $R \$ 12,00$ reais per capita/ano.

2. critérios relacionados à série histórica da produção ambulatorial e hospitalar do SUS, voltados para o financiamento do conjunto de ações e serviços de especializados e de alta complexidade nos municípios habilitados na condição de gestão mais avan çada na $\mathrm{N} O$ vigente. Este mecanismo foi implantado em 1994 com as primeiras habilitações na condição de gestão semiplena municipal da NO básica 01/1993. Nos anos 2000, 
as transferências para os municípios nesta modalidade são estabelecidas através da Programação Pactuada e Integrada (PPI), que permite a explicitação da parcela de recursos recebida para fins de atendimento de pacientes provenientes de outros municípios do estado.

3. critérios diversos: a) relativos ao financiamento do conjunto de ações eserviços de especializados e de alta complexidade nos estados habilitados na condição degestão mais avançada na NO vigente; b) destinados ao financiamento dos programas específicos da atenção básica (Piso de Atenção Básica variável - PAB variável) como, por exemplo, o programa de saúde da família, o programa de agentes comunitários de saúde, a farmácia básica e os incentivos para implantação de ações de epidemiologia e controle de doenças e combateà carência nutricional; c) destinados ao financiamento de ações de média e al ta complexidade em vigilância sanitária (associação decritérios per capita, conjugados a incentivos proporcionais ao volume de arrecadação de taxas de fiscalização); d) relacionados ao Fundo de Ações Estratégicas e Compensação (FAEC) e voltados para grupos prioritários e ampliação do acesso a determinadas ações e serviços; e) associados a formas de remuneração específica de determinadostipos de prestadores (entre eles o mecanismo deremuneração diferenciada de hospitais universitários - o Fator delncentivo ao Desenvolvimento de Ensino e Pesquisa (FIDEPS)- que serve como um instrumento de compensação financeira a unidades que atuam com custos hospitalares diferenciados); f) relacionados a outros programas específicos, entreeles, o programa para aquisição de medicamentos excepcionais e medicamentos para saúde mental.

Os diferentes tipos de transferência federal estão sujeitos às regras previstas na legislação da saúde - existência de Conselho de Saúde, Plano de Saúde e Fundo de Saúde - e nas portarias ministeriais específicas - habilitação nas condições de gestão previstas nas N O, certificação nos programas de atenção básica, cumprimento dos requisitos para o recebimento dos recursos, informação da produção. Apesar dos dispositivos legais e normativos do SUS darem uma certa garantia aos fluxos financeiros, admite-se que todas as formas descritas podem ser interrompidas e seus montantes substantivamente al terados, na medida que estão sujeitas a uma série de variáveis tais como as revisões periódicas dos tetos financei ros e as al terações freqüentes das portarias ministeriais.

É por isso que al guns estudiosos do financiamento da política de saúde no Brasil, mesmo reconhecendo avanços na automaticidade do sistema com os mecanismos detransferência"fundo a fundo" não sujeitos à informação prévia da produção, denunciam seu caráter voluntário, dependente e "tutelado" à esfera federal ${ }^{12,13}$. Pesquisas conduzidas sobre as finanças públicas municipais também classificam as transferências SUS como "transferências negociadas", em conseqüência da especificidade do processo decisório e da regulamentação queinforma o repasse desses recursos ${ }^{14}$.

Ressal ta-seque o repasse de recursos daUnião por contra-prestação de serviços na rede pública e privada credenciada ao SUS até o limite fixado nos tetos financeiros municipais e estaduais vigorou como forma predominante até o final de 1998. Somenteem 1999, a remuneração direta ao prestador passa a representar menos de $50 \%$ do total de recursos da União direcionados para o custeio da assistência, passando a 3,9\% no primeiro semestrede 2004, devido à habilitação progressiva de municípios e estados nas condições de gestão previstas nas $\mathrm{NO}$ e aos mecanismos de transferência "fundo a fundo" a elas atrelados (Tabela 1).

Tabela 1

Participação percentual dos recursos federais do SU S para as ações e serviços de saúde segundo grupos de despesa, Brasil - 1998 a junho de 2004.

\begin{tabular}{lccrrrrr}
\hline Grupo de despesa & 1.998 & 1.999 & 2.000 & 2.001 & 2.002 & 2.003 & 2.004 \\
\hline Remuneração por serviços produzidos & 55,3 & 45,9 & 39,0 & 33,3 & 30,8 & 19,5 & 3,9 \\
Transferências - média e alta complexidade & 29,0 & 32,8 & 36,4 & 40,6 & 40,0 & 47,6 & 61,9 \\
Transferências - atenção básica & 15,7 & 21,3 & 24,6 & 25,1 & 25,4 & 25,8 & 25,9 \\
Transferências do PAB fixo e PAB-A & 13,3 & 15,5 & 14,0 & 12,2 & 11,3 & 11,0 & 11,5 \\
Transferências - ações estratégicas (FAEC) & - & 0,0 & 0,0 & 0,9 & 3,9 & 7,1 & 8,3 \\
Total & 100,0 & 100,0 & 100,0 & 100,0 & 100,0 & 100,0 & 100,0 \\
\hline
\end{tabular}


As transferências SUS também se diferenciam daquelas que ocorrem por meio de mecanismos conveniais estabelecidos com a União para fins de custeio einvestimentos na rede de ações e serviços desaúde. Estes mecanismos permanecem como importantes formas de repasse utilizadas pela União na área da saúde, constituindo-se como transferências tipicamentediscricionárias, na medida em que não são regulados através de dispositivos legais ou pela edição de portarias ministeriais, mas sim pelos dispositivos contidos em cada convênio.

Independente do progressivo aumento das transferências federais, uma questão importante a ser aprofundada diz respeito às condicionalidades estabelecidas para a aplicação desses recursos. O bserva-se uma tendência crescente do M S vincular os recursos transferidos a determinadas políticas e programas definidos no âmbito nacional na tentativa de aumentar seu poder indutor eregulador sobre o sistema. Estesinstrumentos representam formas utilizadas pelo gestor federal para incentivar ou inibir políticas e práticas pelos gestores estaduais, municipais e prestadores de serviços ${ }^{15}$. A prática de vinculação de recursos federais suscita polêmica no quediz respeito à delimitação do poder da União versus o grau de autonomia necessário para que os gestores estaduais e municipais implementem políticas voltadas para a sua real idade local ecompromete a gestão orçamentária destas esferas sem garantir uma maior eficiência e efetividade no gasto.

As potencial idades redistributivas das transferências federais do SUS

Os diversosmecanismose critérios queinformam as transferências SUS determinam capacidades diferenciadas para redistribuição de recursos entre estados e municípios. Cada mecanismo de transferência SUS está atrelado em maior ou menor grau à capacidade instalada e de produção de serviços públicos e privados credenciados ao SUS existente em uma dada jurisdição.

$O$ PAB fixo e o PAB-A são aqueles que mais "fogem" à oferta e produção, pois estão submetidos à lógica per capita. Seus montantes variam segundo a estimativa populacional fornecida pelo IBGE sendo distribuídos, atémeados de 2004, na forma duodécimos mensais para os FMS e FES. Por suavez, os recursos para o financiamento das ações e serviços especializados e de alta complexidade nos municípios são expressão direta do perfil da capacidade instalada e de produção dos serviços existente em seus territórios políticoadministrativos. Isto porque são os sistemas de informação de produção e faturamento do SUS que através da série histórica de gastos fornecem os parâmetros utilizados para a programação das referências intermunicipaisnaPPI edefinição dos montantes financeiros globais repassados mensalmente para os FM S.

No caso dos estados, outros critérios entram nas redefinições sucessivas quese deram ao longo da segunda metade dos anos 90 e início dos anos 2000. Estudo produzido por Souza C. ${ }^{2}$ aponta para a importância das negociações que se dão em torno das emendas parlamentares para alteração das transferências da U nião para os governos estaduais na área da saúde. Em 2000, por exemplo, uma emenda ao orçamento da União, puxada pela bancada da Bahia, alocou recursos adicionais aos tetos estaduais inversamente ao per capita existente, privilegiando os estados do N ordeste.

Os recursos associados ao custeio da assistência ambulatorial e hospitalar no SUS têm representado o principal montante transferido pela União desde 2001 e, se agregado aos recursos do FAEC, foram responsáveis por cerca de $70 \%$ das despesas federais com ações e serviços de saúde atéjunho de2004 (Tabela 1). Esteúltimo, implantado em 1999, é um mecanismo de repasse para efeitos de complementação financeira. Ao longo dos anos, ocorreu uma ampliação de seu escopo com inclusão de incentivos não necessariamente atrelados à oferta e produção. Entretanto, na sua maioria, para ser transferido, o FAEC exige a disponibilidade de um profissional qualificado ou um equipamento sofisticado, o que só é possível em determinados centros de referência, localizados em poucos municípios e estados do país.

Não podemosignorar que o esforço para superação das desigualdades regionais elocais possa prescindir de formas de redistribuição de recursos financeiros pela esfera federal voltado para a maior homogeneidade no financiamento da saúde. Essa é uma importante função a ser desempenhada pelas esferas com elevado poder de arrecadação para correção dos desequilíbrios verticais (entre as esferas de distintos níveis) e horizontais (entre esferas do mesmo nível de governo) no sentido da implantação do caráter nacional e universal da política de saúde.

Entretanto, a diversidade de critérios utilizados não garante à União as condições necessárias para redistribuição de recursos tendo em vista uma maior igualdade na capacidade final de gasto público em saúde das esferas subnacionais de governo. Enquanto alguns estudos ressaltam a 
importância dos mecanismos de transferências específicos criados nosanos 90 (principalmenteo PAB fixo) paraa redução das desigualdades naalocação per capita de recursos federais entre regiões, estados emunicípios ${ }^{16,17,18,19,20}$, outros são mais cautelosos ao exaltar os resultados al cançados.

Particularmente, os estudos de Porto ${ }^{21}$ eU gá et al. ${ }^{11}$ demonstram queo peso da oferta eda produção de serviços restringe o processo de alocação eqüitativa de recursos federais para o custeio do SUS. Os autores apontam como necessários para se al cançar mudanças mais consistentes recursos de investimentos para equilibrar a oferta de serviços existentes; a alocação de recursos adicionais de custeio que contemplem diferentes perfis demográficos, epidemiológicose condições sociosanitárias e estejam orientadas para as maiores "necessidades de saúde" ea maior participação dos estados na correção dos desequilíbrios nos tetos vigentes.

Mattos e Costa ${ }^{22}$ destacam o fato de que, independente dos mecanismos e critérios utilizados para o repasse de recursos financeiros, estes devem ser orientados para a busca da igualdade no total de gastos públicos per capita em saúde, como somatório dos gastos da União, estados e municípios. Desta forma, poderiam ser compensadas as diferençasna capacidadedefinanciamento em saúde dos estados e municípios e respeitados os diversos perfis de morbi-mortalidade existentes no país.

Neste artigo, postula-se que as transferências federais do SU S não favorecem uma mai or igualdade no gasto público em saúde porque: 1) não permitem, na sua maioria, a redistribuição de recursos para estados e municípios com maiores dificuldades orçamentárias, pois sua forte associação com a oferta e produção impede ampliar as receitas disponíveis em estados e municípios com menor capacidade de arrecadação. Estados e municípios mais ricos são os que apresentam maior capacidade de oferta e produção, constituindo o "círculo vicioso" a que se refere Banting $\&$ Corbett $\left.{ }^{23} ; 2\right)$ desconsideram as possibilidades reais deaporte de recursos eampliação de gasto a partir das receitas próprias das esferas subnacionais fruto das regras que informam o federalismo fiscal no Brasil.

\section{Considerações finais}

Estudos recentes sobre o federalismo fiscal no Brasil apontam algumas deficiências do nosso sistema tributário que, apesar de prover uma redis- tribuição interregional de recursos, não atende aos requisitos da equalização fiscal e criação de níveis mais homogêneos na capacidade final de gasto das esferas subnacionais de governo. Pelo contrário, os resultados das pesquisas apontam que as transferências redistributivas, que não guardam relação com as bases tributárias dos governos subnacionais - FPE e FPM , o sistema de cota-parte estadual, o SUS e o Fundef - embora promovam a realocação de recursos tributários do núcleo mais desenvolvido do país para estados mais atrasados, o fazem de maneira "essencialmente aleatória, criando e reproduzindo desigualdades entre unidades da federação tão grandes ou maiores do que aquel as que são observadas na arrecadação inicial" 4 .

Além disso, a importante descentralização fiscal, ocorrida a partir da década de 1980, tornou o Brasil uma das federações com maior autonomia orçamentária dos entes subnacionais. Esta mudança não foi acoplada a um projeto nacional, impôs constrangimentos à esfera federal, privilegiou fortemente a esfera municipal em detrimento da esfera estadual e se caracteriza por forte dependência dos municípios aos recursos transferidos da União.

Os desequilíbrios criados e os imperativos da política de estabilização econômica na década de 1990 geraram reações e tentativas de recentralização de receitas pela União, com impacto significativo no financiamento federal e no processo de descentralização da política de saúde. Por outro lado, as diferentes capacidades de arrecadação e dependência tributária dos estados e municípios apontam para possibilidades distintas de gastos vinculadas às suas receitas proprias disponíveis. As características estruturais do federalismo fiscal, somados à política de ajuste fiscal do governo federal e às desigualdades econômicas e sociais subjacentes, configuram um cenário bastante complexo, onde a disputa por recursos para as ações de saúde se desen rola.

Em relação às regras que orientam as transferências de recursos federais para o financiamento das ações e serviços descentralizados do SUS, estas possuem efeito limitado no que tange à redistribuição fiscal e redução das desigualdades nas receitas voltadas para a saúde. Isto porque, na sua maioria, a distribuição de recursos federais guarda uma forte relação com o perfil da capacidade instalada e com a série histórica de gastos informada nas bases de dados de produção e faturamento do SUS. Os equipamentos e profissionais de saúde disponíveis nos ambulatórios, hospitais e serviços de apoio diagnóstico-terapêutico nos 
diversos estados e municípios, assim como sua capacidade deprodução efaturamento, se expressam deforma bastante heterogênea no território.

0 modelo de federalismo fiscal vigente no Brasil e o padrão preponderante das transferências SUS reforçam-se mutualmente e apontam para uma tendência à redistribuição de recursos tributários no Brasil que não favorece uma maior igualdadeno gasto público em saúde pelos desequilíbrios orçamentários gerados às unidades subnacionais. Com isso, crescem as expectativas dos atores federativos no financiamento federal da política de saúde: da União, pelas possibilidades de condução dos rumos da política nacional através de incentivos financeiros e conformação de parâmetros nacionais; das esferas subnacionais, pelo aporte de novos recursos da saúde que possam compensar suas dificuldades de financiamento e que possibilitem maior autonomia de gestão.

Não por acaso, novas alternativas para o financiamento da política de saúde estão setornando fontes adicionais de recursos financeiros cada vez mais reinvindicadas pel os gestores subnacionais, assim como um importante mecanismo de indução e de amortecimento de tensões regionais utilizado pela União no sentido da correção dos desequilíbrios federativos. De fato, o período que se estende de 1998 atéo início de 2004 émarcado pelo surgimento de alterações nas regras que informam o financiamento federal da política de saúde nos âmbitos municipal eestadual, que não são mais expressão direta da oferta e produção, mas que se subordinam a outras lógicas.

Os critérios, os valores, assim como os requisitos necessários para alocação destes recursos têm sido alvo de discussão das instâncias de representação e gestão intergovernamental do SUS no plano nacional (Conselho Nacional dos Se- cretários deSaúde, Consel ho Nacional dos Secretários M unicipais de Saúde e Comissão Intergestores Tripartite). O bserva-se que a pauta de negociação intergovernamental écada vez mais dominada por diversas regras de financiamento federal da política de saúde que são permanentemente modificadas.

No interior destas instâncias, as decisões sobre as regras que informam estas transferências refletem as formas como vêm sendo administradas as tensões federativas e as disputas territoriais por recursos federais. Entretanto, o grau de desigualdade subjacente dos municípios e estados brasileiros, a falta de um planejamento integrado dos diversos critérios que regem as transferências SUS, assim como o entendimento das transferencias da saúde como um componentedo sistema de partilha tributário da federação acabam por reforçar determinados padrões de assimetria e gerar novos desequilíbrios orçamentários, dificultando a compensação das desigualdades na capacidade de gasto público em saúde das esferas subnacionais.

Se a literatura disponível possibilita a discussão sobre os condicionantes institucionais vinculados ao federalismo fiscal eao padrão detransferências federais hegemônico no SUS, pouco se sabe acerca das negociações que envolvem as transferências federais do SUS eos resultados dos acordos firmados. É preciso a realização de trabalhos empíricos queevidenciem: 1) o padrão de relações intergovernamentais nas negociações políticas específicas sobre os diversos tipos de transferências de recursos federais do SUS atualmente vigentes; 2 ) as potencialidades redistributivas de cada mecanismo de transferência financeira utilizado pela União para compensação das desigual dades na capacidade de gasto público em saúde das esferas subnacionais. 


\section{Referências}

1. Gagnon AG. The political uses of federalism. In: Burgess M , Gagnon AG, organizadores. Comparative federalism and federation. Competing traditions and future directions. Toronto: University of Toronto Press; 1993. p. 15-44.

2. Souza C. Federalismo e conflitos distributivos: disputa dos estados por recursos orçamentários federais. Dados 2003; 46(2):345-384.

3. RezendeF. M odernização tributária e federalismo fiscal. In: Rezende F, Oliveira FA, organizadores. D escentralização e federalismo fiscal no Brasil. Desafios da reforma tributária. Rio de Janeiro: Konrad Adenauer; 2003. p. 25-38.

4. Prado S. Distribuição intergovernamental de recursos na federação brasileira. In: Rezende F, Oliveira FA, organizadores. Descentralização e federalismo fiscal no Brasil. Desafios da reforma tributária. Rio de Janeiro: Konrad Adenauer; 2003. p. 41-125.

5. Dain S. Visões equivocadas de uma reforma prematura. In: Affonso RBA, Silva PLB, organizadores. Reforma tributária e federação. São Paulo: FU N DAP; 1995. p. 43-74.

6. Secretaria do Tesouro Nacional. 0 que você precisa saber sobre o FPM eFPE. Brasília: Secretaria do Tesouro Nacional, M inistério da Fazenda; 1998.

7. Prado S, Quadros W, Cavalcanti CE. Partilha de recursos na federação brasileira. São Paulo/Braślia: FAPESFUNDAP/IPEA; 2003.

8. Dain S, Faveret ACSC, Cavalcanti CE, Carvalho D, QuadrosWL. A avaliação dos impactos de reforma tributária sobre o financiamento da saúde. In: Negri B, Giovanni G, organizadores. Brasil. Radiografia da saúde. Campinas: UNICAM P; 2001. p. 233-288.

9. Lessa C, Salm C, Soares LT, Dain S. Pobreza e política social: uma leitura da questão da exclusão nos Anos 90. Praga - Estudos M arxistas 1997; 3: 63-87.

10. Silva M M AC. 0 processo de endividamento dos estados: problemas e limites à descentralização e à autonomia [dissertação]. Rio de Janeiro (RJ): Instituto de Economia, Universidade Federal do Rio de Janeiro; 1998

11. U gá M A, Piola SF, Porto SM, Vianna S. Descentralização e alocação de recursos no âmbito do Sistema Único de Saúde (SUS). Rev C S Col 2003; 8(2): 417-437.

12. M edice AC, M aciel MS. A dinâmica do gasto social nas três esferas de governo: 1980-92. In: Affonso RBA, Silva PLB, organizadores. D escentralização e políticas sociais; 1996. p. 41-105.
13. Carvalho G. A inconstitucional administração pósconstitucional do SU Satravés denormas operacionais. Rev C S Col 2001; 6(2): 435-444.

14. Instituto Brasileiro de Geografia eEstatística. Pesquisa de informações básicas municipais. Perfil dos municípios brasileiros. Finanças públicas 1998-2000. Rio de Janeiro: IBGE; 2004.

15. Machado CV. Regulação da política nacional de saúde: estratégias e tendências. In: Negri B, Viana ALD, organizadores. O SU S em dez anos de desafios. São PauIo: Sobravime/CEALAG; 2002. p. 505-529.

16. Costa NR, Pinto LF. Piso de atenção básica: mudanças na estrutura. In: N egri B, Viana ALD, organizadores. O SUS em dez anos de desafios. São Paulo: Sobravime/ CEALAG; 2002. p. 271-297.

17. M elamed C, Costa NR. Inovações no financiamento fe deral à atenção básica. Rev C S Col 2003; 8(2):393-401.

18. Marques RM, M endes A. Atenção básica e programa de saúde da família (PSF): novos rumos para a política de saúde e seu financiamento? Rev C S Col 2003; 8(2): 403-415.

19. Souza RR. Redução das Desigualdades Regionais na Alocação dos Recursos Federais para a Saúde. Rev C S Col 2003; 8(2):449-460.

20. Souza RR. 0 financiamento federal do SUS: mitos e verdades. In: N egri B, VianaALD, organizadores. O SUS em dez anos de desafios. São Paulo: Sobravime/CEALAG; 2002. p. 411-437.

21. Porto SM. Equidad y distribuición geográfica de recursos financieros en los sistemas de salud. Cad Saúde Pública 2002; 18(4):939-957.

22. Mattos RA, Costa NR. Financiando o SUS: algumas questões para o debate. Trabalho, Educação e Saúde 2003; 1(2):315-333.

23. Banting K, Corbett S. Federalismo y políticas de atención a la salud. In: Foro de Federaciones, Instituto $\mathrm{Na}$ cional para el Federalismo y Desarrollo M unicipal, organizadores. Federalismo y políticas de salud. D escentralización y relaciones intergubernamentales desdeuna perspectiva comparada. Ottawa: Foro de Federaciones; 2002. p. 5-41.

Artigo apresentado em 22/06/05

Aprovado em 26/06/2006

Versão final apresentada em 02/10/06 